\title{
El Atragantamiento en el cine de Pedro Almodóvar. Análisis de Dolor y Gloria
}

Eva Hernández Martínez | evhern01@ucm.es

Universidad Complutense de Madrid

\author{
Palabras clave \\ "Almodóvar", "cine”, “síntoma”, “deseo”, “análisis \\ textual", "psicoanálisis” \\ Sumario \\ 1. Introducción. \\ 1.1. Objetivos. \\ 1.2. Hipótesis. \\ 2. Metodología. \\ 3. Análisis. \\ 3.1. La regresión y el flashback. \\ 3.2. Síntoma y atragantamiento. \\ 3.3. Operadores textuales en La fiera de mi \\ niña y la filmografía de Almodóvar. \\ 3.4. Operación simbólica. \\ 3.5. Metaficción: El Primer Deseo. \\ 3.6. La gloria del autor: dar forma al dolor \\ 4. Conclusiones. \\ 5. Bibliografía.
}

\section{Resumen}

El presente trabajo propone un análisis de varios fragmentos de Dolor y Gloria (Almodóvar, 2019) con la metodología del análisis textual a fin de deletrear lo referido al síntoma mayor del personaje: el atragantamiento. Este trabajo pretende dar cuenta del carácter regresivo del film y su relación con los numerosos flashbacks (en total, más de un 30\% del metraje). El cuerpo del protagonista aparece convertido en síntoma, incapacitándole para amar y trabajar. A lo largo del análisis se estudia la conflictiva del protagonista para desear y sus esfuerzos para elaborar la muerte de la madre. Se traza una comparativa entre Bringing up Baby (Howard Hawks, 1938) y Dolor y Gloria a partir del análisis de la primera propuesto por González Requena donde explica la utilización de dos operadores textuales recurrentes en la filmografía almodovariana: el hueso y el tigre. El punto de llegada será el deletreo del primer deseo de Salvador Mallo, alter ego del director, Pedro Almodóvar. La principal aportación consiste en la identificación de cierto atragantamiento de lo femenino y lo materno en los personajes masculinos de la filmografía de Almodóvar; más concretamente, en el film Dolor y Gloria.

\section{Cómo citar este texto:}

Eva Hernández Martínez (2021): Atragantamiento en el cine de Pedro Almodóvar. Análisis de Dolory Gloria, en Miguel Hernández Communication Journal, Vol. 12 (1), pp. 243 a 266. Universidad Miguel Hernández, UMH (Elche-Alicante). DOI: https://doi. org/10.21134/mhcj.v12i.347 


\section{Choking on Pedro Almodóvar's cinema. Pain and Glory Analysis}

Eva Hernández Martínez | evhern01@ucm.es

Universidad Complutense de Madrid

Keywords

"Almodóvar", "cinema”, "symptom”, “desire”, “textual analysis", "psychoanalysis"

Summary

1. Introduction.

1.1. Objectives.

1.2. Hypothesis.

2. Methodology.

3. Analysis.

3.1. Regression and flashback.

3.2. Symptom and choking.

3.3. Textual operators in La fiera de mi niña and Almodóvar's filmography.

3.4. Symbolic operation.

3.5. Metafiction: El Primer Deseo.

3.6. The glory of the author: shaping the pain.

4. Conclusions.

5. Bibliography.

\section{Abstract}

This work analyzes several sequences from the film Pain and Glory (Almodóvar, 2019) using textual analysis method. Pain notion, which articulates the film, is proposed as a starting point of this analysis. Salvador's body is a symptom itself, keeping him away from loving and working. Throughout the analysis we are going to study the difficulties of Almodóvar's alter ego to desire and his great efforts to elaborate her mother's death. The point of arrival in the analysis will be Salvador Mallo's first desire, which happens to be different from what the spectator might have thought.

This work proposes an analysis of Pain and Glory (Almodóvar, 2019) using textual analysis methodology in order to spell out what refers to the main symptom of the character: choking. This work points out the regressive nature of the film and its relationship with the numerous flashbacks (in total, more than $30 \%$ of the footage). Salvador's body is a symptom itself, keeping him away from loving and working. Throughout the analysis we are going to study the difficulties of Almodóvar's alter ego to desire and his great efforts to elaborate her mother's death. A comparison is made between Bringing up Baby (Howard Hawks, 1938) and Pain and Glory from the analysis of the first one proposed by González Requena where he explains the use of two recurring textual operators in Almodovarian filmography: bone and tiger. The point of arrival in the analysis will be Salvador Mallo's first desire, which happens to be different from what the spectator might have thought. The main contribution consists in the identification of choking with the feminine and the maternal in the masculine characters in Almodovar's filmography; more specifically, in the film Pain and Glory.

\section{How to cite this text:}

Eva Hernández Martínez (2021): Atragantamiento en el cine de Pedro Almodóvar. Análisis de Dolory Gloria, en Miguel Hernández Communication Journal, Vol. 12 (1), pp. 243 a 266. Universidad Miguel Hernández, UMH (Elche-Alicante). DOI: https://doi. org/10.21134/mhcj.v12i.347 


\section{Introducción}

La filmografía de Almodóvar ha sido objeto de estudio académico desde distintos campos: la sociología, el análisis cinematográfico, el estudio de la producción, la teoría queer y los estudios de género e incluso desde la psicología y otros campos afines.

Muchos sectores de la sociedad se han interesado -desde sus primeras producciones- por el personal retrato de España que proponía Almodóvar. No solo en España, sino que los públicos internacionales también han querido conocer su cine y hacer la experiencia de ver una de las películas que lanzaba el director. Almodóvar ha sido percibido por los académicos dedicados a la teoría fílmica como el autor sucesor de Luis Buñuel o Saura (Vernon y Morris, 1995: 14), dando cuenta de las numerosas atenciones que ha recibido desde sus inicios y por su personalísimo estilo.

Francisco Martínez Cano explica cómo el cine de Almodóvar se puede ver "como lugar de construcción de la identidad de género [homosexual]" (2020: 218); un espacio de encuentro donde hombres y mujeres invierten sus roles habituales y se desatan las pasiones más profundas.

Como plantea González Requena, "el cineasta escribe [literalmente] en la pantalla” (2020) a través de una escritura lo suficientemente creativa para sorprender y lo convenientemente general para poder llegar a públicos dispares.

El académico Pedro Poyato propone que en el último periodo del cine de Pedro Almodóvar se "abandona la comedia de tintes domésticos y provocadores" (2016: 9) para fundirse con un drama pasional. Y acierta aún más cuando lo define como un "drama manifiestamente corporal y vertebrado en torno al deseo, el dolor, la pérdida y la muerte”. Esta definición de drama corporal podría ser empleada para definir Dolor y Gloria (2019), donde el personaje principal, un director de cine, construye una narrativa alrededor de tres películas: Sabor, Dolor y Gloria y El Primer Deseo. Tres relatos, dos de ellos pertenecientes a la diégesis, que terminan por hacer uno solo: pasado, presente y futuro del director.

Dolor y Gloria continúa con la tradición de películas de Almodóvar que hablan sobre directores de cine, repitiendo y reelaborando uno de sus temas recurrentes: el cine dentro del cine. El presente trabajo trata de analizar, mediante el trabajo del análisis textual, las claves para deletrear el drama corporal depositado en Dolor y Gloria; drama que, por otra parte, contribuye a pensar el resto de la filmografía de Almodóvar.

Dolor y Gloria, así como el resto de su filmografía, es un lugar excepcional para estudiar la dialéctica entre lo femenino y lo masculino; siempre teniendo en cuenta que ambas construcciones podrían estar invertidas o simplemente no corresponderse con el sexo biológico del personaje.

El presente artículo aborda el atragantamiento, hecho físico que constituye uno de los síntomas principales de Salvador. Se atraganta de forma constante y a partir de la operación para conseguir que esto deje de sucederle Salvador conseguirá desatrangantar algo de sus viejas problemáticas - tan viejas como la relación con su madre o sus dolores de espalda- 
y rodar su última película, El primer Deseo. A lo largo del artículo se propone un análisis del personaje principal, Salvador, y de este síntoma: el atragantamiento de lo femenino. Entendemos, entonces, que el atragantamiento alude a la imposibilidad de Salvador de simbolizar o de integrar parte de lo femenino y de lo materno. La muerte de la madre se convierte en un punto decisivo para el director de cine evidenciado en los múltiples flashbacks salpicados a lo largo de todo el film.

\subsection{Objetivos}

Se propone desentrañar el sentido de la enunciación de Dolor y Gloria, buscando dónde se hallan el dolor y la gloria a lo largo del film. Se enumeran a continuación los objetivos fijados por el analista:

I. Dar cuenta del carácter regresivo del film y del abundante uso del flashback.

II. Deletrear los síntomas propuestos por la enunciación.

III. Analizar un operador textual clave en el relato: el hueso.

IV. Analizar la construcción subjetiva del personaje protagonista, Salvador Mallo.

V. Explorar el universo metaficcional que propone Dolor y Gloria.

VI. Deletrear la escritura misma del texto almodovariano.

\subsection{Hipótesis}

Existe en Salvador una imposibilidad para tragar adecuadamente; debido al crecimiento desproporcionado de un hueso de la columna, el espacio para que los alimentos circulen se ha reducido tanto que se atraganta constantemente. Prácticamente se atraganta hasta con el agua. Se propone que en el cine de Almodóvar en general, y en particular en Dolor y Gloria, existe cierto atragantamiento de los personajes masculinos con lo femenino.

Se propone como pregunta de investigación la etiología de tal hecho. ¿Proviene el atragantamiento de Salvador de la relación asfixiante con su madre? ¿O de la ausencia paterna? Se propone como hipótesis que ambas circunstancias - una madre estragante y un padre ausente- construyen en Salvador Mallo una estructura subjetiva con tintes melancólicos -ciertamente histérica-. El film propone que la causa de tal atragantamiento es el crecimiento desproporcionado de un hueso cervical, pero, ¿qué sentido tiene en la narración esa osificación? Otra pregunta de investigación accesoria trata de aclarar dónde está «la gloria» del mismo título del film: ¿es el acto artístico la única tarea capaz de desanudar los síntomas -lo no dicho- del cuerpo del álter ego del director manchego? 


\section{Metodología}

La metodología utilizada para la realización de la investigación es el análisis textual, que toma como referencia a la semiótica, el psicoanálisis y la antropología.

Jesús González Requena en una sesión de su seminario anual de la Facultad de Ciencias de la información del año 2019 ha listado cuatro principios del análisis textual:

El primero consiste en hacer la experiencia del texto. Recorrerlo, precisamente, como un lugar donde queda cristalizada la experiencia del autor primero, y después la del analista o espectador. Habrá que sortear un gran obstáculo que algunos no están dispuestos ni siquiera a considerar; la resistencia mayor que se puede dar en este tipo de análisis y que suscita hartas controversias: los contenidos no se desarrollan solo en el plano consciente, sino también en el inconsciente. Hay que atreverse a hacer la experiencia del texto que, a nivel inconsciente, nos interpelará intensamente.

Los siguientes principios se dan de manera simultánea y no son exactamente sucesivos.

El segundo consiste en no tratar de entender de forma inmediata, procurando no deshacerse de la subjetividad. A través de la escritura, el artista deposita en ella cierto saber aun "sin saber lo que quiere decir" (González Requena, J. 2008b: 83); el entendimiento -del lado de la comunicación- se sitúa en el campo opuesto al saber:

Tal es, entonces, el territorio en el que se desenvuelve la experiencia del artista, y también, desde luego, la de su espectador: el de un saber que se sitúa fuera del ámbito de lo que puede ser entendido, es decir: codificado y comunicado. Pero que constituye a la vez, sin embargo, el territorio de un saber -allí donde, insistamos, el saber no se confunde con el entender sustantivo- (Ibid.)

Se trata, por tanto, en un primer momento no entender; a pesar de que a continuación el analista -a través del propio análisis- trate de explicar algo de la experiencia contenida en el texto.

El tercero está ligado al anterior y al posterior, y es se asemeja al principio de parsimonia. Consiste en demorar lo más posible el momento de entender. Para ello, será fundamental el cuarto principio: el deletreo moroso de cada uno de los elementos analizados. Si se lee -rápidamente- se ignora la letra, por eso lo llamamos deletreo.

El método de análisis del presente artículo será la aplicación de estos cuatro principios descritos por el análisis textual propuesto por González Requena.

Muchas de las secuencias prólogo de las grandes obras del cine tienden a resumir en líneas generales el resto del film. La secuencia prólogo enuncia, no en pocas ocasiones, el meollo de la cuestión que se pretende abordar. Incluso se puede hallar de forma implícita un planteamiento, nudo y desenlace. Y este lugar privilegiado del film, como también lo es el centro temporal de una película, es el que se elegirá para comenzar el análisis. El análisis textual, como metodología, propone para comenzar el análisis localizar el punto de ignición. Este será el lugar del texto donde el relato quema al sujeto (González Requena, J. 
1995: 37) que en este caso se evidencia en forma de cicatriz en la espalda de Salvador. El punto de ignición elige de forma frecuente el principio, final o mitad del metraje y no en pocas ocasiones, además, toma la forma de memoria de un accidente (Torres, L. 2017a: 89). Lorenzo Torres lo propone en los siguientes términos: se trata de reelaborar la subjetividad a partir de una quemadura evidente, es decir, lo que podemos localizar en Dolor y Gloria en forma de cicatriz u operación lumbar.

De esta manera, se propone a partir de la localización del punto de ignición -que identificamos en la cicatriz y en los mismos síntomas del protagonista- hacer un análisis textual de determinadas escenas del film.

Además, se recurrirá al análisis de dos operadores textuales en la película de Bringing up Baby (Howard Hawks, 1938) y su comparativa con Dolor y Gloria para dar cuenta de la problemática del protagonista, Salvador Mallo.

\section{Análisis}

\subsection{La regresión y el flashback}

Dolory Gloria (Almodóvar, 2019) comienza con una secuencia en la que Salvador Mallo flota en el agua ${ }^{1}$. Está sumergido con los ojos cerrados, su rostro aparece relajado, casi como si estuviera meditando. La piscina aparece convertida en un gran vientre. Se respira esa misma tranquilidad en la que está un niño antes de desalojar esa primera morada que constituye el cuerpo materno ${ }^{2}$.

Y si la historia comienza en el minuto 00:00:01:34 (inmediatamente antes aparecen los títulos de crédito de apertura), el director no se demora (minuto 00:00:02:02) en mostrar al espectador el cuerpo lacerado de Salvador en la piscina del Hotel Miguel Ángel. Aparece señalado así el punto de ignición del film sobre el cual se vertebrará el análisis dado el interés que suscita como punto narrativo mayor. En forma de cicatriz se anuncia uno de los temas centrales de la película y del presente texto: el dolor.

Salvador recuerda $a^{3}$ entonces a su madre tendiendo la ropa en el río junto a otras lavanderas mientras cantan $A$ tu vera. En este fragmento, sin embargo, no se anticipa nada del futuro dolor que al protagonista le espera, las aguas del río en continúo movimiento están carentes aún de enfermedad (Hernández, E. 2020).

${ }^{1}$ Este planteamiento está directamente relacionado con la experiencia real del director. En una entrevista para El Mundo (Luis Martínez, 18 de marzo de 2019) cuenta cómo durante las vacaciones de verano acostumbraba a sumergirse en la piscina para disfrutar la sensación de ingravidez del agua, siendo este el único momento en el que no le dolía nada. Fue entonces donde concibió el comienzo de la película.

${ }^{2}$ Freud describe las fantasías de regreso al seno materno y de renacimiento como fantasías primordiales comunes en los seres humanos. Puede consultarse lo referente a ello a lo largo de su obra en especial en El Malestar en la Cultura (1929 [1930]) o en De la historia de una neurosis infantil (1918 [1914]).

${ }^{3}$ Más tarde sabremos que, más que recordar, lo que hace es visualizar la película que grabará: El Primer Deseo. 
Arrancamos el análisis con uno de los enunciados que da cuenta del estado de Salvador:

Salvador [voz en off]: Empecé a conocer mi cuerpo a través del dolor y las enfermedades.

Lo corporal, para Salvador, está unido al sufrimiento; y no le falta razón. Lo real del cuerpo es siempre un problema para los seres humanos, sobre todo si el cuerpo se muestra limitado: cuando la enfermedad aparece de forma azarosa. O quizás, de forma no tan azarosa.

Salvador [voz en off]: Además de los tínitus y las sibilancias, mi especialidad son los dolores de cabeza, migrañas, cefaleas de tensión o en racimo, y dolores de espalda. [...] Pero no todo es tan físico e ilustrable, también padezco penalidades abstractas, dolores del alma, como el pánico y la ansiedad, que añaden angustia y terror a mi vida y que, naturalmente, alterno desde hace años con la depresión.

Todo su cuerpo aparece convertido en síntoma. Algo cortocircuita el orden de la palabra. Aunque se ilustran y enumeran sus múltiples dolencias, pareciera que la etiología de tales sufrimientos está oculta. ¿Cuál es el motivo o las causas de tales síntomas? ¿A qué lugar apuntan los síntomas físicos y psíquicos de Salvador?

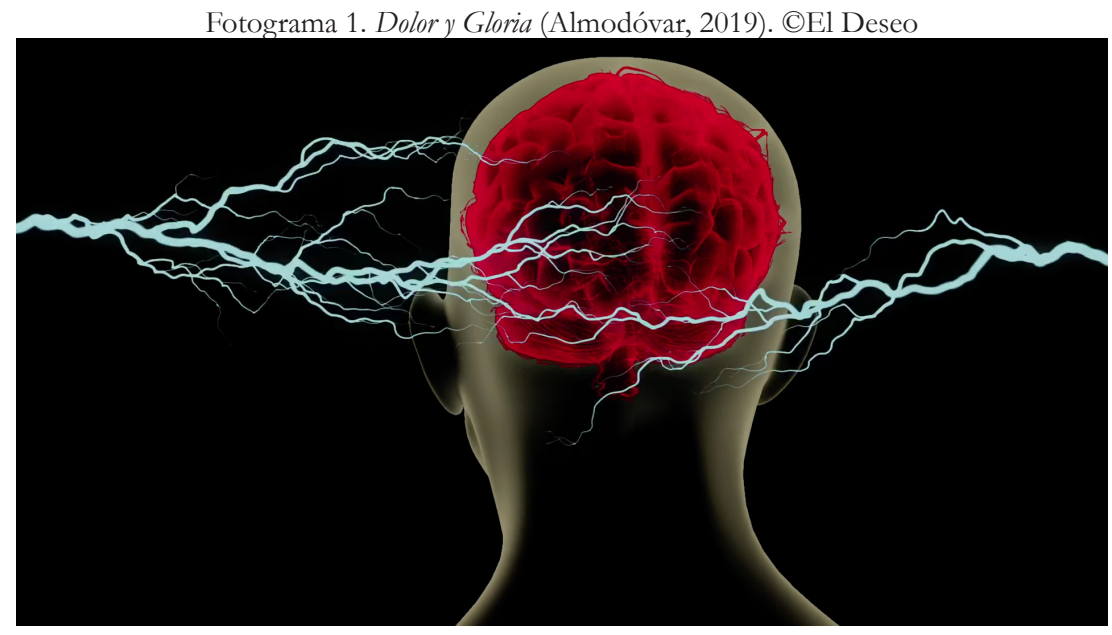

Dado que la película tiene por título, Dolor y Gloria, nos detendremos en el dolor ${ }^{4}$ o en los síntomas que recorren la película y la articulan.

Salvador: Pero pronto descubri que mi cabeza y lo que babia dentro de ella, además de ser fuente de placer y conocimiento, entrañaba infinitas posibilidades de dolor.

${ }^{4}$ No se busca la causa orgánica de estos síntomas como tal, sino los motivos por los que existen determinados dolores y enfermedades en un texto artístico que, necesariamente, apuntan hacia un lugar. Es decir, buscamos el sentido de los síntomas o el mismo sentido de la enunciación. 
Y si dice que vivió los treinta primeros años con relativa inconsciencia, Salvador empieza pronto a somatizar parte de eso inconsciente en su cuerpo. Así pues, queda nombrado el origen de estos dolores físicos y mentales: la cabeza. O dicho de otra manera, su vida psíquica.

La imagen misma así lo dice: Salvador -convertido ahora en imagen vectorial a modo de ilustración médica- es un sujeto atormentado psíquicamente. Los rayos golpean directamente su cerebro (Fotograma 1), el encargado de producir la percepción sensorial localizada y subjetiva que padece.

Los síntomas no son equivalentes a enfermedad, más bien deben ser considerados como "actos perjudiciales o inútiles" por los cuales el que los sufre -pues siempre llevan cierta cuantía de sufrimiento o displacer- "hace un gasto energético superior" al de estando sano. Si la lista de síntomas es extensa, supondrá para el sujeto una "parálisis para todas las tareas importantes de la vida" (Freud, S. 1916-7a). Desde el psicoanálisis se entiende que un sujeto enfermo es el que no está en disposición de amar y trabajar. ¿No es eso mismo lo que no puede hacer Salvador? ¿Acaso no permanece aislado emocionalmente y alejado del trabajo a causa de sus dolores?

Los síntomas aparecen como sustitutos de la satisfacción frustrada. Esto es posible gracias a la regresión de la libido a épocas anteriores del desarrollo del individuo:

[...] sabemos que el neurótico quedó adherido a algún punto de su pasado; ahora nos enteramos de que en ese periodo su libido no echaba de menos la satisfacción y él era dichoso. Busca entonces a lo largo de toda su biografía una época así, [...] tal como lo recuerda o tal como se lo imagina en virtud de incitaciones más tardías (Ibid.: 33).

Salvador se sustrae a épocas pasadas en esos flashbacks tan insistentes. Llegan a cobrar casi tanta importancia como el presente desde el que se narra la película. De la hora y cincuenta y tres minutos que ocupa la película los flashbacks suponen treinta y seis minutos y cuarenta y dos segundos 5 . El espectador, en esos ensueños, descansa por un momento del tormento del director.

Tabla 1. Duración de la película y los flashbacks

\begin{tabular}{|l|l|}
\hline Duración de la película & $00: 01: 53: 03$ \\
\hline Duración total de los flashbacks (10) & $00: 00: 36: 42$ \\
\hline Duración de los flashbacks de la niñez ${ }^{6}(8)$ & $00: 00: 27: 34$ \\
\hline Duración de los flashbacks de Salvador adulto (2) & $00: 00: 09: 08$ \\
\hline
\end{tabular}

Elaboración propia

${ }^{5}$ Se han contabilizado los flashbacks de la niñez de Salvador (en total 8 veces se interrumpe la película) y en los que es adulto (dos veces es interrumpido el curso de la narración en presente).

${ }^{6}$ Más que un recuerdo estos flashbacks forman parte del proceso de grabación de la película El primer deseo, dirigida por Salvador Mallo, alter ego del cineasta Pedro Almodóvar. 


\subsection{Síntoma y atragantamiento}

Si sabemos que el origen del dolor está en el psiquismo, pues así lo dice el texto mismo "pero pronto descubrí que mi cabeza y lo que había dentro de ella, además de ser fuente de placer y conocimiento, entrañaba infinitas posibilidades de dolor"-, ¿cuál es la etiología de este sufrimiento psíquico? Debemos detenernos en el síntoma mayor manifiesto en el film, el que de alguna forma pone en movimiento el desarrollo narrativo: el atragantamiento (fotograma 2). El mismo personaje lo dice: "Joder, me atraganto con nada". El film muestra a Salvador y su múltiple sintomatología: dolores de cabeza, depresión, insomnio, aislamiento...Pero lo que sigue apareciendo en el centro es su problema más inmediato: "come poco y se atraganta muchísimo". Así lo sabemos por una alusión en un diálogo de Maya y Mercedes. Salvador comenzará a recurrir a las drogas a partir del reencuentro con el protagonista de una de sus primeras películas, Sabor. ¿Para calmar el dolor o para soñar con sus recuerdos de infancia?

Estas ensoñaciones suponen un retroceso al tiempo en el que el principio del placer reinaba soberano, constituyen fantasías diurnas con las que el sujeto se sustrae de su realidad actual. Él mismo dice que la mayor parte del tiempo está en este estado, en duermevela. Y la teoría psicoanalítica puede ayudar a dilucidar el origen de estas fantasías: “[...] en la actividad de la fantasía el hombre sigue gozando de la libertad respecto de la compulsión exterior, esa libertad a la que hace mucho renunció en la realidad" (Ibid.: 339).

Fotograma 2. Dolor y Gloria (Almodóvar, 2019). CEl Deseo

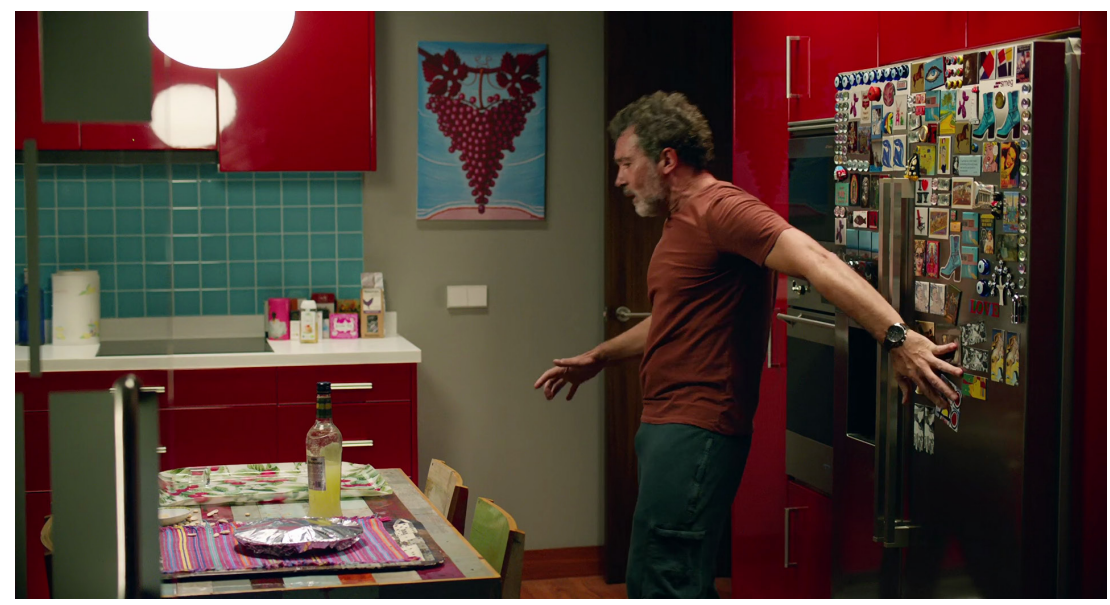

En el universo de Salvador, sin embargo, algo desarticula -aunque no inmediatamenteestos viajes al pasado: la llegada de Federico.

El beso y el reconocimiento de la excitación sexual por ambas partes, en definitiva, el deseo, hacen que Salvador, de forma un tanto maniaca, se permita buscar una solución a sus 
síntomas. Llama a Mercedes inmediatamente, sin siquiera percatarse de la hora, y le pide una cita con el médico.

Salvador acude pronto a consulta pues quiere deshacerse de los síntomas que le habían impedido trabajar. "Bueno, cuéntame Salvador", el doctor Galindo, le pregunta así por sus síntomas. Es un relato lo que el doctor espera de él.

Dolores de espalda, depresión, drogadicción, asma, tensión, insomnio y migrañas. El doctor interrumpe para preguntarle por qué no trabaja.

Doctor Galindo: Hay gente que está peor que tú y sale adelante.

Salvador: Lo sé, lo sé, pero yo no he sido capaz. Mi madre murió hace cuatro años y a los dos años me operé de la espalda. Creo que todavía no me he recuperado, ni de una cosa, ni de la otra. Necesito ayuda, doctor.

El doctor Galindo, que es claramente un médico ocupado de lo mecánico, acierta a decirle que trabajar le vendría bien; aunque no escucha -u obvia- el comentario sobre la madre. Resuelve cambiarle la oxicodona por otro opiáceo. Pero esto no es lo que Salvador necesita. El espectador, sin embargo, ya lo sabe. Hay algo con la madre esperando ser tramitado, ¿acaso es ella misma la que debe de salir de él? Y en lo sucesivo esto se confirmará, pues la película mostrará inmediatamente una serie de flashbacks donde Salvador recuerda los últimos días con su madre. Habla con ella, sobre todo. A continuación, Salvador se disculpa y sale de la consulta dejando a Mercedes a cargo de la situación:

Mercedes: Hay algo más doctor... Salvador se atraganta con frecuencia. Hace una bora, cuando veníamos al hospital, solo por beber un poco de agua creí que se ahogaba. El digestólogo le ha hecho una endoscopia y ba descubierto un bulto que le presiona el esófago, por eso se atraganta tan fácilmente. Y no sabemos qué es ese bulto.

Así pues, parece que se trata de un bulto que presiona. Hacia el final de la película se enunciará, en términos médicos, aquello que provoca ese atragantamiento constante. "No hay tumor. Eso está totalmente descartado", dice la radióloga. Salvador, sin embargo, dice que algo debe pasarle pues se atraganta hasta con purés. La causa, según aclara la doctora, es la osificación de una vértebra que ocasiona que el espacio por el que pasan los alimentos sea prácticamente inexistente. La respuesta de Salvador termina por aclarar el asunto:

Salvador: ¿Por qué ba crecido tanto ese bueso abí?

Esta es la pregunta de Salvador desde su posición de paciente. Y él está justamente ahí, en un diván (fotograma 3), tratando pensarse. Esa es la pregunta que debemos responder, pero antes debemos pensar: ¿de qué hueso habla Salvador? 
Salvador: ¿Y se puede hacer algo?

Digestóloga [en tono relajado`]: Una cirugía, hay que quitarte esa osificación cuanto antes.

Fotograma 3. Dolor y Gloria (Almodóvar, 2019). CEL DESEO, D.A., S.L.U.- Foto: Manolo

Pavón

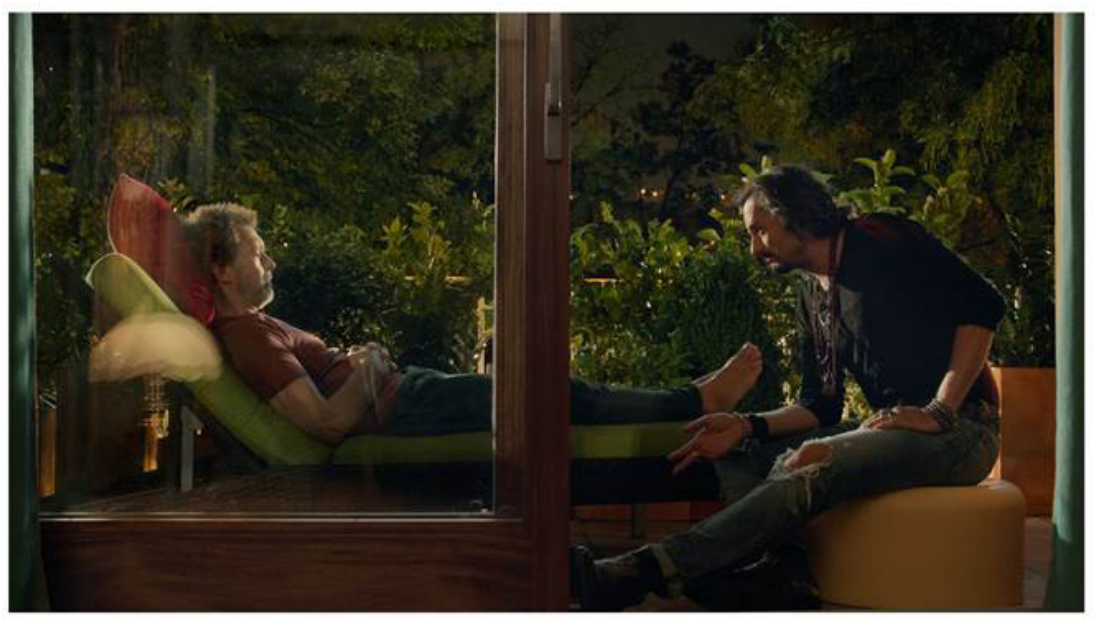

\subsection{Operadores textuales en La fiera de mi niña y la film- ografía de Almodóvar}

Llegados a este punto, es preciso hacer un alto en el camino para introducir una idea que hará avanzar el análisis. La fiera de mi niña o Bringing up Baby (Howard Hawks, 1938) es una película que seguramente vio el autor del guion en una de sus múltiples experiencias cinematográficas. Nos referimos ahora a Pedro Almodóvar.

\footnotetext{
${ }^{7}$ No deja de llamar la atención la tranquilidad que aporta la doctora ante la futura operación. Tampoco, que el escogido para hacer de traumatólogo sea un hombre y, sin embargo, la ocupada de decir el resultado final sea una mujer. De cualquier forma, el que realice la operación será el doctor Galindo, o al menos, así lo vemos en el quirófano, dispuesto a operar. Conviene leer la cita de Freud que podría aclarar esta elección inconsciente: "entre los acontecimientos que siempre retornan en la historia juvenil de los neuróticos [está] [...] la amenaza de castración. [...] Así no es nada raro que un muchacho se tome la mala costumbre de jugar con su miembro sin saber que es preciso ocultar esos manejos, y los padres $[. .$.$] amenacen con cortarle el miembro o la mano pecadora. [...] Si es la madre$ o una persona del sexo femenino quien la formula, suele achacar su ejecución al padre o al...médico" (Freud, S. 1916-17: 336). Para Freud, no obstante, es improbable que esta amenaza se haga como tal en todos los casos, por lo que propone que el niño se compone esa amenaza ante su saber de que "la satisfacción autoerótica está prohibida". Más tarde, habiendo visto los genitales femeninos, mediante la fantasía completa su teoría y la da por buena. Los personajes, así, podrían reconducirse a una figura materna amenazadora y a una paterna potencialmente castradora.
} 
Bringing up Baby trata sobre un arqueólogo que, casi por azar, conoce a una joven que le ocasiona múltiples problemas. Ella se enamora de él nada más verle y no deja de confesarle su deseo, pero David se resiste casi hasta el final de la película. Existen dos objetos, dos operadores textuales, que cobran una especial relevancia. González Requena hace un detallado análisis de cómo operan en el film.

Resumiendo, hecho que complica la labor del analista ${ }^{8}$ al presentar el análisis al lector, la situación puede ser resuelta como sigue:

Tabla 2. Operadores textuales en Bringing up Baby

\begin{tabular}{|l|l|l|l|}
\hline Apoyo visual & Personaje & Identificación & Operador Textual \\
\hline Fotograma 4 & David & Masculino & Hueso \\
\hline Fotograma 5 & Susan & Femenino & Leopardo \\
\hline
\end{tabular}

Fotograma 4. Bringing Up Baby

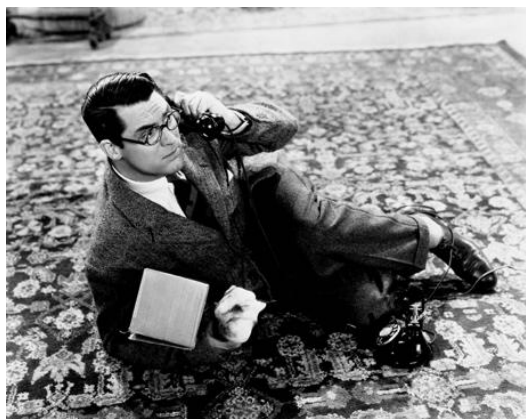

Fotograma 5. Bringing Up Baby

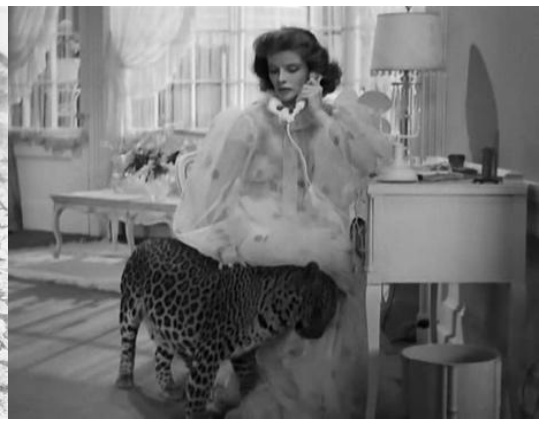

Cada uno, posee así, un objeto. Jesús González Requena (2008a) explica que David tiene un hueso que protege con celo y lleva a todos los sitios (fotograma 4). Susan, por su parte, tiene un leopardo, del cual se quiere deshacer (fotograma 5). O más bien, quiere que David se ocupe de él. El zoólogo, espantado por el animal -y preocupado por la integridad de su hueso-, rechaza todo encuentro con el felino.

El leopardo viene a nombrar la pulsión que habita en el cuerpo de la mujer y hace referencia a sus partes pudendas. Se coloca en el lugar de la experiencia a la que se enfrenta el hombre ante el genital femenino: una ausencia vivida como amenaza.

Así pues, si toman en serio el aprecio que le tiene David a este hueso, realmente «una costilla»" de un animal prehistórico, podrán darse cuenta de que remite, como aclara González Requena, al falo imaginario (2008a: 218).

${ }^{8}$ Una nota metodológica accesoria: el análisis textual propone la lectura morosa del texto. Debe procurarse no entender inmediatamente, sino retrasar lo máximo posible el momento de entender. Hay tres momentos en el análisis: ver, comprender y concluir. 


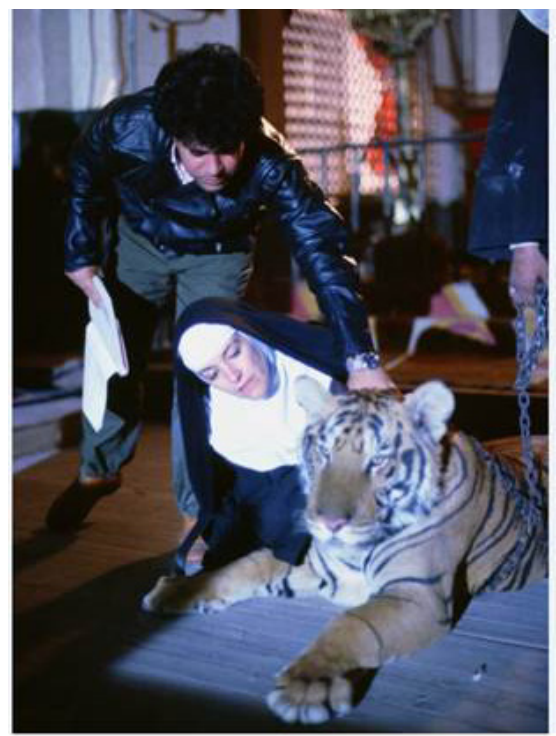

Hueso y pene no están tan alejados. Un dato que ayuda a colegir esta unión es que el pene humano es el único -de los miembros de los mamíferos- que no tiene un hueso interno: báculo. Aparentemente, el hombre lo perdió a lo largo de la evolución, pues los primates sí lo conservan (Gilbert, S., \& Zevit, Z., 2001). Una prueba suplementaria que confirma esta hipótesis es que Almodóvar está muy cerca de esta película y de la problemática que rescata. Más o menos consciente de esto, pone un tigre ${ }^{10}$ en Entre Tinieblas (1983) (fotograma 6). $\mathrm{Y}$, aunque es cierto que cambia de felino, le llama igual que el leopardo de Bringing up Baby: El niño ${ }^{11}$.

${ }^{9}$ Existe aquí una analogía con el hueso que le debiera faltar a Adán, el primer hombre: una costilla. ¿Acaso no fue este el elemento que utilizó Dios para crear a la mujer? Por otra parte, si al hombre le falta algún hueso no es precisamente la costilla, sino el báculo (Gilbert, S., \& Zevit, Z., 2001).

${ }^{10}$ Dirá Almodóvar sobre el tigre en una entrevista: «Habla con los pajaritos [refiriéndose a Sor Perdida, interpretado por Carmen Maura, la monja dueña del tigre], las gallinas y los conejos como si fueran sus hijos. Al tigre lo llama "niño" porque lo ha criado ella. [...] Es un personaje secundario que solo tiene un primer plano en toda la película, cuando se despide del tigre y llora porque no soporta dejarle" (1988: 83). Es decir, la existencia de este operador textual común a ambas películas las relaciona íntimamente: en ellas dos mujeres con ardientes deseos poseen un "hijo" al que deben cuidar. No obstante, ambas finalmente quieren deshacerse de él: Susan porque le parece un buen motivo para encontrarse con David, y Sor Perdida porque ante el cierre del convento cree que no va a poder ocuparse de él, dándoselo a la única pareja [heterosexual] que queda en pie: la del cura del convento y Sor Víbora.

${ }^{11}$ Esta analogía no pasa desapercibida por Freud, quien así lo describe: "El pequeño, que originariamente se refería al miembro viril, ha podido, pues, pasar secundariamente a 


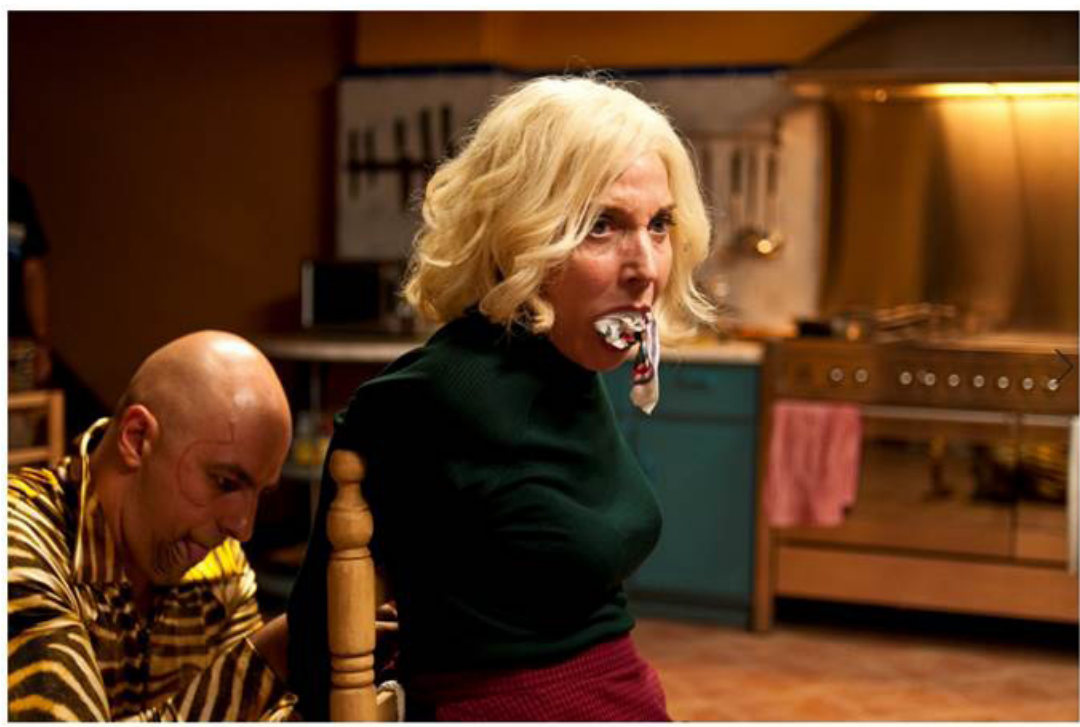

Más adelante, en su película La piel que habito (Almodóvar, 2011) el director retoma la analogía entre tigre e hijo-niño ${ }^{12}$ (fotograma 7$)$.

\subsection{Operación simbólica}

Hecho este recorrido, estamos en disposición de plantear la siguiente cuestión: ¿qué tipo de operación es la de quitar ese hueso tan crecido? Queda claro, que Salvador quiere que se lo quiten cuanto antes. Se le ve incómodo con esa hipertrofia ${ }^{13}$ suya (fotograma 8).

designar los genitales femeninos" (1917c: 119). Más adelante dirá: "Si se investiga con la suficiente profundidad la neurosis de una mujer, no es raro toparse con el deseo reprimido de poseer un pene como el varón". Justamente esta idea encontrará un representante en el film, nada menos que el primer enunciado: "Me gustaría ser un hombre para bañarme en el río desnuda” (Hernández-Martínez, E., 2020).

${ }^{12}$ El hijo de una de las protagonistas, Marilia, acude a la casa-laboratorio disfrazado de tigre. El atuendo incluye en la zona de la pelvis una cara de dicho felino (fotograma 7), acentuando así la intensa relación entre tigre y genitales (en este caso masculinos).

${ }^{13}$ Aunque el hueso que aparece nombrado en la película es una vértebra, se propone que existe cierto desplazamiento hacia la nuez, una prominencia de la laringe propia del varón. El desplazamiento de vértebra a nuez es una marca de lo masculino; la nuez, como el pene, es una protuberancia en exclusiva del varón. Además, la nuez se pone en relación con lo oral, ligado directamente con la problemática melancólica de Salvador. Puede verse esta incomodidad con el atragantamiento a lo largo de la película en el gesto del personaje de llevarse la mano a la garganta (fotograma 8). 
Fotograma 8. Dolor y Gloria (2019). CEL DESEO, D.A., S.L.U.- Foto: Manolo Pavón

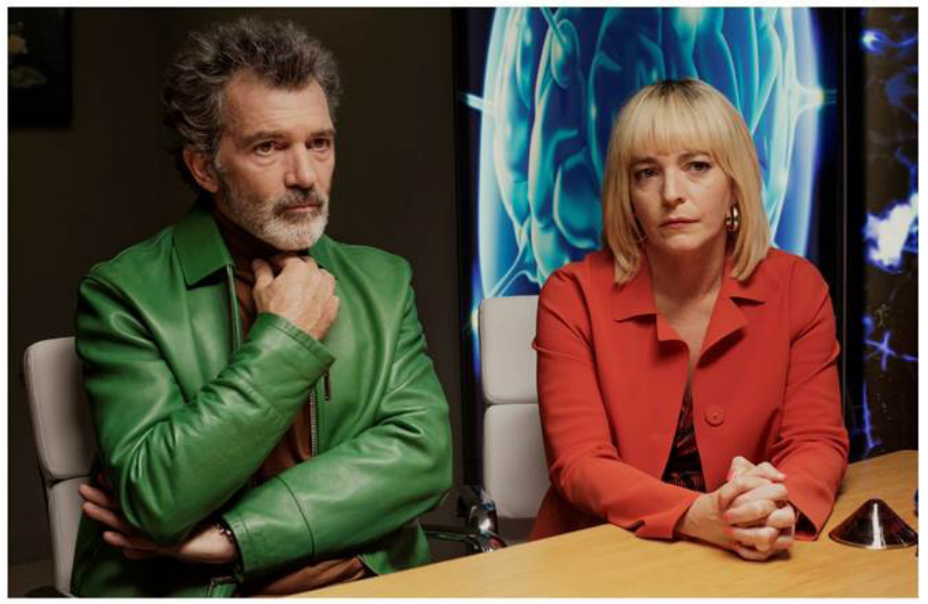

Y si el hueso equivale a el falo, el lector podrá resolver sin ninguna timidez la ecuación. La operación debe ser, necesariamente, una encargada de retirar lo que produce ese atragantamiento constante. Podríamos decirlo así: tramitar su parte masculina es un obstáculo para Salvador. Elaborar la posición femenina y su identificación con la figura materna se constituyen como puntos de llegada de su labor artística.

Y esta no es la primera operación de tales características en el cine de Pedro Almodóvar. Hubo una antes, donde el mismo actor que ahora interpreta a Salvador, fue el encargado de hacer una operación para eliminar el pene de un varón (fotograma 9). Una vaginoplastia, en este caso.

Fotograma 9. La piel que habito (Almodóvar, 2011). CEL DESEO, D.A., S.L.U.- Foto: Lucía Faraig

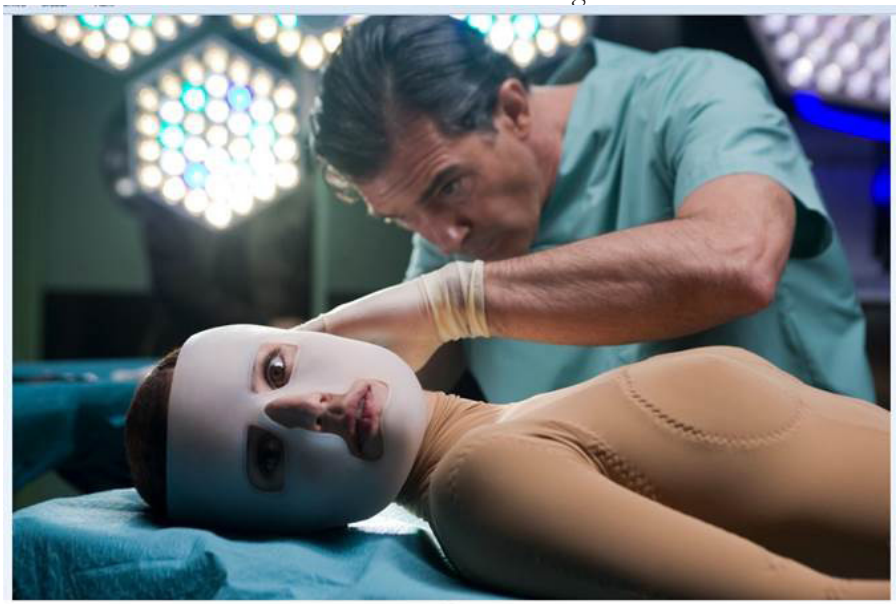


Después de la diversidad y abundancia de transexuales y travestis en sus películas, reconociendo las diferencias entre ambos casos, una operación de estas características se llevaba a cabo en el cine de Almodóvar; pues aunque había transexuales poblando el universo almodovariano, estos conservaban los genitales masculinos $-\mathrm{O}$ al menos, no se daba ninguna pista para pensar lo contrario-. Uno de estos personajes, la Agrado, declaraba en Todo sobre mi madre (Almodóvar, 1999) cómo ella conservaba el miembro viril, pues a pesar de ser una mujer -hecha a sí misma-, sus clientes preferían que tuviera pechos y pene (Sánchez, J.L., 2017: 447).

En La piel que habito esta operación se produce sin el consentimiento del sujeto sometido a tal operación, poniendo de relieve un deseo inconsciente que habita al sujeto y por el que a la vez, siente pavor: convertirse en mujer a partir de la castración de su cuerpo.

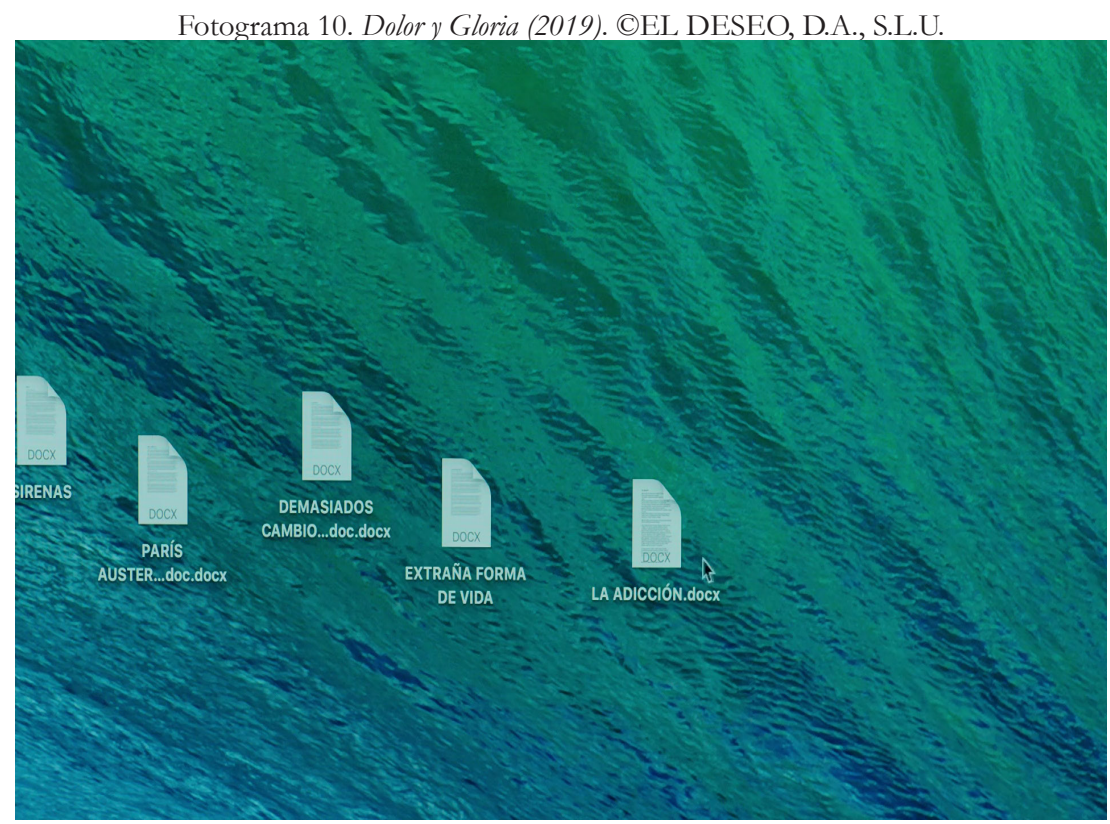

Si se presta atención a los títulos escogidos por Salvador para sus guiones ${ }^{14}$ (fotograma 10), la cosa queda mucho más clara: desvío, madres paralelas, demasiados cambios de género, extraña forma de vida, sirenas y replicantas (entre otros que aparecen en el escritorio del ordenador de Salvador). Todos parecen apuntar a un camino de construcción de la feminidad en el sujeto masculino de tintes ominosos.

\footnotetext{
${ }^{14}$ Podemos verlos tanto en la pantalla del ordenador de Salvador en un plano subjetivo que corresponde a la mirada curiosa de Alberto como en el guion de la película presentado por el propio director el 21 de noviembre de 2019 en la editorial Reservoir Books. ${ }^{15}$ Decimos que es colateral pues se produce en tanto que existe en la madre cierto deseo dirigido hacia este joven, desencadenando así que la mirada de Salvador se focalice en él.
} 
En Dolor y Gloria, más que una operación real, hay una operación simbólica: una operación destinada a desatragantar el deseo del protagonista. Posibilitará que Salvador pueda finalmente grabar su próxima película. Supone, por tanto, que pueda haber una elaboración del primer deseo a través de la labor artística: un rodaje cinematográfico.

\subsection{Metaficción: El Primer Deseo}

A pesar de que en un primer visionado el espectador podría decir que el primer deseo del niño apunta al obrero, el análisis del texto desenmascara otra posible solución. Lo que se pone en el centro es el primer deseo, sí; pero no precisamente uno dirigido a Eduardo, pues este es solo colateral ${ }^{15}$. Realmente, el primer deseo no podría ser otro que el dirigido a la madre. Encontramos un punto de anclaje de esta hipótesis en la banda sonora de la película; la primera vez que aparece la canción Come Sinfonia (Mina \& Giuseppe Donaggio, 1961) es en el minuto 95 (fotograma 11), justo antes del momento en el que espectador medio señalaría, en un primer visionado, el primer deseo de Salvador.

Esta canción se instala en la banda sonora tres veces a lo largo del film: la primera cuando Salvador se introduce en la máquina de TAC; la segunda cuando recuerda del desmayo y la tercera en la escritura del recuerdo mismo cincuenta años después. Se teje así un nexo entre estos tres momentos íntimamente relacionados por la letra de esta canción: todos tienen como núcleo el recuerdo de lo que Salvador considera El Primer Deseo. No obstante, en la letra de la canción encontramos una de las claves que ponen en relación la aparición de estas fantasías o flashbacks con lo materno -más que con Eduardo-:

\begin{tabular}{|l|l|}
\hline Come sinfonía (italiano) & Come sinfonía (español) \\
\hline Sogno, sogno & Sueño, sueño \\
E tu sei con me & y tú estás conmigo \\
Chiudo gli occhi e in cielo splende già & Cierro los ojos y ya brilla en el cielo \\
una luce. & una luz. \\
Io sogno & Yo sueño \\
D'esserti vicino e di baciarti & estar cerca de ti y besarte \\
E poi svanire & y luego desaparecer \\
In questo sogno irreale & en este sueño irreal. \\
[... & {$[\ldots]$} \\
Ascolto e & Escucho y \\
Ti sento ancora più vicino & te siento ahora más cerca \\
La musica che sento è & La música que escucho es \\
Ė come sinfonia & es como una sinfonía \\
Lassì sento gli angeli & Puedo escuchar los ángeles allí \\
Che cantano per noi & que cantan para nosotros. \\
Io vorrei, io vorrei & Yo querría, yo querría \\
Che questo sogno fosse realtà & que este sueño fuera realidad \\
Realtà d'un sogno, amor & Realidad de un sueño, de amor. \\
\hline
\end{tabular}

${ }^{15}$ Decimos que es colateral pues se produce en tanto que existe en la madre cierto deseo dirigido hacia este joven, desencadenando así que la mirada de Salvador se focalice en él. 
Fotograma 11. Dolor y Gloria (2019). CEL DESEO, D.A., S.L.U.- Foto: Manolo Pavón

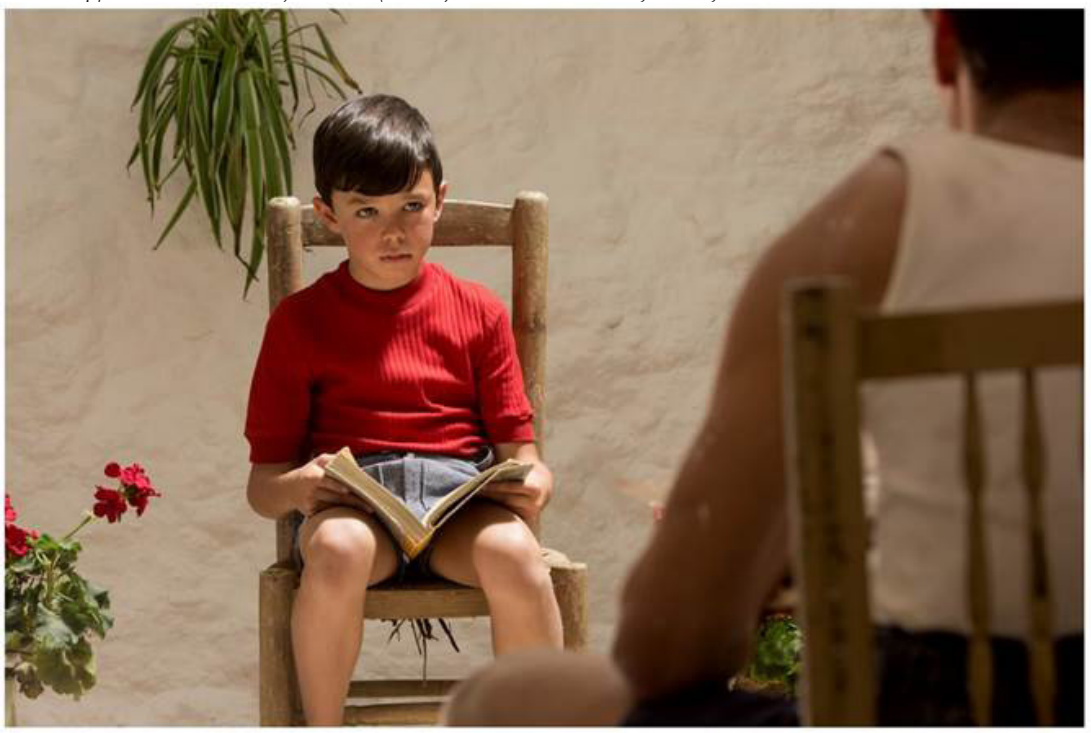

Si se presta atención y se lee al pie de la letra la misma letra de la canción se verá más clara la relación del desmayo del niño con el deseo y su madre:

$$
\begin{aligned}
& \text { Sueño, sueño } \\
& \text { y tú estás conmigo } \\
& \text { [...] } \\
& \text { Yo querría, yo querría } \\
& \text { que este sueño fuera realidad } \\
& \text { Realidad de un sueño, de amor. }
\end{aligned}
$$

Si tendemos un puente entre la canción y la realidad de Salvador, el director fantasearía para volver a reencontrarse con el amor materno de la tierna infancia. Podemos verlo en el primer recuerdo, donde un Salvador aún muy pequeño no ha llegado todavía a Paterna; es decir, está todavía en el universo Materno de la identificación imaginaria.

En los flashbacks donde el protagonista es ya adulto, Salvador recuerda la enfermedad de la madre. La sucesión de memorias, que realmente está narrando a Mercedes, termina con un autorreproche, un lamento:

Mercedes: Hiciste todo lo que pudiste.

Salvador: Sí, pero ella quería morir en el pueblo. Y yo le habia prometido llevarla. La pobre murió en la UCI de un hospital sola. 
Existe entre Salvador y Jacinta, su madre, una profunda identificación ${ }^{16}$. La pérdida de la madre puede considerarse incluso el desencadenante de su operación inmovilizante de espalda. Él mismo se lo dice al doctor: no se ha recuperado ni de la muerte de su madre, ni de la operación. La infancia se evidencia así como un lugar de "choque" donde frecuentemente los padres ${ }^{17}$ se convierten en agentes de determinado tipo de violencia (Torres, L. 2017b: 79).

El insomnio, la repulsa del alimento -que aquí podríamos entender como la incapacidad de Salvador para tomar alimentos sólidos- y la escasa capacidad para el amor y el trabajo hablan de un duelo no resuelto o en el límite, de una melancolía. En el caso de la melancolía se produce una fuerte rebaja en el sentimiento de valía que se exterioriza en autorreproches y autocastigos (Freud, S. 1917b) presentes a lo largo de la película a través de la enfermedad y de las escenas finales con la madre. Salvador recuerda en estas conversaciones ${ }^{18}$ cómo ella no lo tenía por un buen hijo. Acepta de buena gana la culpabilidad que le lanza la madre sin cuestionarse. Es un claro movimiento de aceptación de un vínculo ambivalente: consiente el castigo porque se sabe en algo culpable.

La autopunición, por otra parte, es un medio para el castigo del objeto de amor: el enfermo consigue desquitarse de los objetos originarios a través de un rodeo sin tener que mostrar la hostilidad de forma directa (Ibid.).

${ }^{16}$ También la hay entre el mismo Pedro Almodóvar con su madre. El libro de Nuria Vidal, El cine de Pedro Almodóvar, es una excelente guía en forma de entrevistas al director donde puede constatarse, además, que la identificación de Salvador tiene algo que ver con la del propio director. Dirá su hermano Agustín Almodóvar: "La verdad es que lo ha hecho muy bien [convertirse en el cabeza de familia después de la muerte del padre] [...]. Hay muchas cosas de Pedro que están en mi madre. Cuando la gente la conoce, de repente, entiende un montón de cosas" (1988: 114). Declaraciones del todo reveladoras que explican muy bien la identificación profunda de los personajes masculinos almodovarianos con las mujeres. No quiere decir esto, en cualquier caso, que la mujer sea venerada sobre todas las cosas: es una relación ambivalente. Existe también un deseo inconsciente, como el de Salvador, de deshacerse de ella.

${ }^{17}$ Poco o nada se dice sobre el padre de Salvador. Aparece como una figura ausente cuya ausencia mayor se evidencia cuando Salvador tiene el golpe de calor: él debía de estar allí, pero está en el bar-presumiblemente-. Sobre la figura ausente del padre en la filmografía de Almodóvar se puede consultar Nada sobre mi padre (González Requena, 2020) donde se expone la tesis que el mismo título del film Todo sobre mi madre evidencia "un nada sobre mi padre".

${ }^{18}$ Basilio Casanova en su artículo sobre La Inmaculada Concepción en el cine de Almodóvar resalta en uno de sus epígrafes: "Una madre tremenda con la que no se puede hablar" (2019:73). ¿Y se puede hablar con esta madre? Salvador lo intenta, sin duda, aunque solo consigue hacerlo recordando -en forma de flashbacks-. 
Fotograma 12. Dolor y Gloria (2019). CEL DESEO, D.A., S.L.U.- Foto: Manolo Pavón

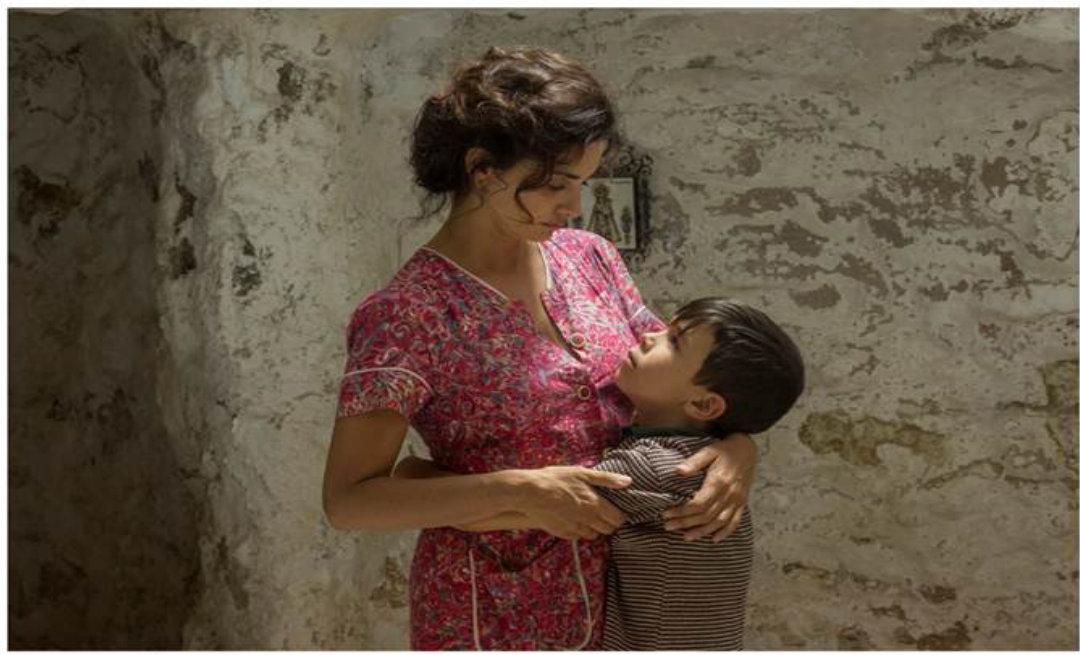

\subsection{La gloria del autor: dar forma al dolor}

Volviendo al primer deseo, si deletreamos la escena en la que Salvador sucumbe a él, podemos ver cómo esta situación se produce en un emplazamiento emblemático para el protagonista: debajo de la claraboya. Ese es el lugar donde vemos a Salvador mirar a Jacinta con unos ojos inundados por el deseo (fotograma 12). Una mirada arrobada propia de los niños hacia sus madres que Salvador mantiene durante todo el film hacia los personajes femeninos, tanto cuando es niño como adulto.

La luz de esta ventana abierta al cielo (que cuenta con una homóloga en el techo de la sala de espera del hospital) funciona como huella mnémica del deseo dirigido a la madre. Esa primera experiencia estética condiciona la segunda, cuando ve por sorpresa el cuerpo desnudo del obrero. Lo que sucede allí es justamente un encuentro sexual: toparse con la diferencia sexual resulta, tal y como describe González Requena el concepto, "intolerable e improcesable" (1995: 23) para el pequeño Salvador. Su orden imaginario y narcisista, en tanto identificado con esa potencia materna, se tambalea al comprobar la "hendidura" materna (Ibíd.).

Cuando las fantasías diurnas de Salvador son transcritas, la energía libidinal del artista en paro se pone a disposición de la creación artística. El principio del placer cede paso al de realidad y el director de cine encuentra una vía para la satisfacción: la sublimación. Y así mismo lo nombrará Freud:

Existe, en efecto, un camino de regreso de la fantasía a la realidad, y es... el arte. Al comienzo, el artista es también un introvertido, y no está muy lejos de la neurosis. Por eso [...] transfiere todo su interés, también su libido, a las formaciones de deseo de su vida fantaseada, desde las cuales abre un camino que puede llevar a la neurosis. [...] y es bien conocida la frecuencia con que justamente los artistas padecen de una inbibición parcial de su productividad, provocada por neurosis (1916-17a: 342). 
Y después del dolor... ¿dónde está la gloria? El artista ${ }^{19}$, como habíamos sugerido anteriormente, es capaz de movilizar su energía libidinal dotándola de forma: "se las ingenia $[\ldots]$ para elaborar sus sueños diurnos de tal modo que pierdan lo que tienen de excesivamente personal y de chocante para los extraños para que estos puedan gozarlos también" (Ibid:: 343).

No acaba aquí el trayecto, el artista genuino es capaz de alcanzar lo que solo alcanzaba en su fantasía: "honor, poder, y el amor de las mujeres" ${ }^{20 "}$ (Ibid:: 343). De nuevo, Freud describe a la perfección el fin del director de cine a través de sus películas: obtener la gloria de ser uno de los grandes artistas españoles. Es ahí donde está la gloria de la película, en el milagro de la creación artística.

Salvador utiliza las drogas para volver y elaborar todo sobre su madre en un afán de resolver ese laberinto de pasiones que supone para cualquier niño el primer amor con su madre. Y cómo no, poder elaborar el dolor que conlleva la pérdida de la madre cuando el sujeto está masivamente identificado ${ }^{21}$ con ella y su posición femenina.

\section{Conclusiones}

Dolor y Gloria es una obra cinematográfica que destaca por su intertextualidad; Almodóvar referencia en esta película de 2019 casi todos sus trabajos previos enlazando personajes, historias, temas... convirtiéndose casi en un epílogo de su filmografía. El carácter regresivo del film y del abundante uso del flashback, después del análisis, se relacionan con el carácter melancólico de Salvador, álter ego de Pedro Almodóvar. Igualmente, la sintomatología depositada en el film da cuenta de una violencia vuelta hacia sí; aquella que debía ir destinada a la madre es finalmente devuelta hacia el sujeto en forma de síntomas incapacitantes para amar y trabajar. A partir del nexo entre la película La fiera de mi niña se demuestra cómo

${ }^{19}$ Basilio Casanova explica que Almodóvar, como artista, es capaz de "retomar algo que quedó en su día pendiente y que solo la capacidad formal de [este] puede, en un momento dado, resolver" (2015: 28).

${ }^{20}$ No puede decirse que no estén interesados los directores de las dos películas analizadas, Salvador Mallo y Pedro Almodóvar, en las mujeres por su orientación sexual. Justamente, por lo excesivo de su amor a ellas, habría de considerarse más que válida esta idea.

${ }^{21}$ En la filmografía de Almodóvar hallamos varios textos donde directores de cine son protagonistas del film. Basilio Casanova resalta la identificación del director de La Ley del deseo (Almodóvar, 1987), Pablo Quintero, con una figura materna -con la misma Virgen María- cuando al final de la película Antonio (Antonio Banderas) se suicida. Casanova llama la atención sobre esto: "una versión en este caso de La Piedad: la madre y el hijo muerto" (2015: 66). La identificación masiva del director mismo (de Pablo) con la figura materna cristaliza en esa última escena y deriva en la inevitable muerte del sujeto: Antonio. González Requena advierte también el mismo tipo de estructura en Todo sobre mi madre (Almodóvar, 1999) donde el hijo, Esteban, se sacrifica para hacer posible el deseo materno (2015). En Dolor y Gloria existe, sin embargo, cierta evolución de esta escena. En esta, aunque el hijo, Salvador, se identifica con la figura materna es finalmente capaz de separarse de ella y constituirse en el lugar de hijo. Y sobre todo: no es objeto de sacrificio como lo son tantos otros hijos en la filmografía del director manchego. 
dos operadores textuales del texto clásico encuentran equivalentes directos en el trabajo de Almodóvar; un recorrido necesario para comprender el crecimiento desproporcionado del hueso de Salvador. La hipertrofia de su hueso tiene que ver con la propia construcción de la feminidad de los personajes masculinos del cine almodovariano: hay ciertamente un atragantamiento con lo femenino y lo materno. Las madres en el cine de Almodóvar son enormes y hablar con ellas se vuelve una tarea compleja para los varones de sus textos. La solución para el hombre pasará, para Salvador ${ }^{22}$, por el acto artístico. Dotar de forma a cierta verdad subjetiva e íntima a través de los textos artísticos que escribe en el papel y en la pantalla misma se constituye como el punto de llegada del director de cine. Es ahí donde, a partir del dolor, halla la gloria.

\section{Bibliografía}

Almodóvar, P., Garzo, G. \& Pavón, M. (2019). Dolor y gloria. Barcelona: Reservoir Books.

Casanova Varela, B. (2019). La Mancha en el cine de Pedro Almodóvar. Trama y Fondo, 46, pp. 25-32.

- (2015). La Inmaculada Concepción en el cine de Pedro Almodóvar. Trama y Fondo, 39, pp. 59-76.

Freud, S. (1984 [1916-1917a]). 23 conferencia. Los caminos de la formación de síntoma. En Freud, S., Etcheverry. J., Freud, A., \& Strachey, J. (Eds.), Volumen 16, Obras completas: Conferencias de introducción al psicoanálisis: (1916-1917), pp. 326-344. Argentina: Amorrortu editores.

- (1993 [1917b]). Duelo y Melancolía. En Freud, S., Etcheverry. J., Freud, A., \& Strachey, J. (Eds.), Volumen XIV, Obras completas: Contribución a la bistoria del movimiento psicoanalitico. Trabajos sobre metapsicología y otras obras: (1915-1916). Argentina: Amorrortu editores.

Gilbert, S., \& Zevit, Z. (2001). Congenital human baculum deficiency: The generative bone of genesis 2:21-23. American Journal of Medical Genetics, 101(3), pp. $284-5$.

González Requena, J. (2020). Nada sobre mi padre. Documento presentado en XIX Jornadas de Historia y Análisis Cinematográfico, Valencia, España. Recuperado de http:// gonzalezrequena.com/

- (2015, 19 abril). La escena y el deseo de la madre. Todo sobre mi madre, All About Eve. Recuperado 23 febrero, 2020, de http://gonzalezrequena.com/todo-sobre-mi-madre-allabout-eve/

${ }^{22}$ En el nombre elegido para el protagonista no deja de resonar cierta iconografía religiosa constante en el cine de Almodóvar. Salvador aparece como un significante equivalente al significante hijo; el Salvador como hijo de Dios aparece como representante de todos los hijos. Este hecho textual apunta de forma directa a que la problemática que aborda el film tiene que ver con la relación del hijo con lo materno, con el "ser hijo" de Salvador Mallo. 
- (2008a). Lo masculino y lo femenino: la costilla y el leopardo. En Avatares de la diferencia sexual en la comedia cinematográfica, pp. 125 -187. Granada: Trama y Fondo y Diputación de Granada.

-(2008b). Apólogo de la bicicleta. O de por qué el arte no tiene gran cosa que ver con la comunicación. La Puerta FBA, 3, 75-96.

- (1996). El texto: tres registros y una dimensión. Trama y Fondo, 1, pp. 3-33.

- (1995). Frente al texto fílmico: el análisis, la lectura. A propósito de El Manantial de King Vidor en González Requena, J. (ed). El análisis cinematográfico. Teoría y práctica del análisis de la secuencia. Madrid: Complutense.

Hernández Martínez, E. (2020). El análisis textual. Aplicación práctica en la secuencia prólogo de Dolor y Gloria (Almodóvar, 2019). En I. Jiménez Gómez, \& R. Eguizábal Maza (Eds.), Métodos y prácticas en el estudio de la comunicación. Madrid, España: Fragua.

Martínez-Cano, F.J. (2020). El cine como tecnología de género. Transgresiones formales en la construcción de la identidad sexual en el cine de Almodóvar. En E. Hernández Martínez et. $\mathrm{Al}$ (Eds.), Construcciones culturales y politicas del género. Sevilla, España: Dykinson.

Sánchez, P. (2015). Identidad visual y forma narrativa en el drama cinematográfico de Almodóvar. Madrid: Editorial Síntesis.

Sánchez Noriega, J.L. (2017). Universo Almodóvar. Estética de la pasión en un cineasta posmoderno. Madrid: Alianza Editorial.

Torres Hortelano, J.L. (2017a). Locura y compromiso del héroe en Homeland y Sully. Comunicación y Hombre. 2017, no 14, pp. 85-101.

— (2017b). Padres ausentes: el cine de Kore-eda Hirozazu. Trama y Fondo, 42, pp. 80-96.

Vernon, K. M., Morris, B., \& Morris, B. (1995). Post-franco, postmodern: The films of Pedro Almodóvar. Greenwood Press.

Vidal, N. (1988). El cine de Pedro Almodóvar. Barcelona: Destino libro.

\section{Agradecimientos}

Este trabajo incluye material fotográfico gracias a la colaboración de EL DESEO y Juan Gatti. En especial, Sergio Rey (EL DESEO), ha colaborado en la búsqueda de material fotográfico en el archivo de EL DESEO. 
MHCJ Vol. 12 (1) | Año 2021 - Artículo no 12 (179) - Páginas 243 a 266 - mhjournal.org

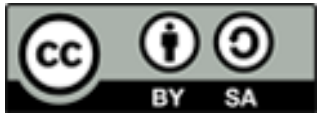

Licencia Creative Commons

Miguel Hernández Communication Journal mhjournal.org

\section{Cómo citar este texto:}

Eva Hernández Martínez (2021): Atragantamiento en el cine de Pedro Almodóvar. Análisis de Dolory Gloria, en Miguel Hernández Communication Journal, Vol. 12 (1), pp. 243 a 266. Universidad Miguel Hernández, UMH (Elche-Alicante). DOI: https://doi. org/10.21134/mhcj.v12i.347 